\title{
Susceptibility of calves to challenge with Salmonella typhimurium 4/74 and derivatives harbouring mutations in htrA or purE
}

\author{
Bernardo Villarreal-Ramos, ${ }^{1}$ Jacquie M. Manser, ${ }^{1}$ Robert A. Collins, ${ }^{1}$ \\ Victoria Chance, ${ }^{1}$ P. David Eckersall, ${ }^{2}$ Phillip W. Jones ${ }^{1}$ \\ and Gordon Dougan ${ }^{3}$
}
1 Institute for Animal Health, Compton, Berkshire RG20 7NN, UK
2 Biochemistry Section, Glasgow Veterinary School, Bearsden Rd, Glasgow G61 1QH, UK
3 Department of Biochemistry, Imperial College of Science, Technology and Medicine, London SW7 2AZ, UK

Author for correspondence: Bernardo Villarreal-Ramos. Tel: +44 1635578 411. Fax: +44 1635577263. e-mail: Bernardo.Villarreal@bbsrc.ac.uk

\begin{abstract}
Salmonella typhimurium $\mathbf{4 / 7 4}$ is highly virulent for cattle after oral challenge, causing severe diarrhoea, which is sometimes associated with systemic spread of the micro-organism. Although susceptible to oral challenge, groups of cattle were found to be relatively resistant to subcutaneous challenge with this strain. The virulence of $S$. typhimurium 4/74 harbouring mutations in htrA and purE was also assessed in cattle. Although S. typhimurium 4/74 htrA and purE are attenuated following oral challenge in mice, cattle were highly susceptible to oral challenge with these mutants. As with the parent $S$. typhimurium 4/74 strain, cattle exhibited greater susceptibility to oral compared to subcutaneous challenge with $S$. typhimurium htrA and purE mutants. Following subcutaneous challenge with sublethal levels of $S$. typhimurium 4/74, calves produced significant levels of antibodies to $S$. typhimurium soluble extract. No correlation was detected between interferon gamma levels in sera and susceptibility to infection by any route. The concentrations of the acute-phaseassociated protein haptoglobin were increased in the sera of five of six cattle inoculated subcutaneously, although increases in concentration were smaller in cattle inoculated orally.
\end{abstract}

Keywords: Salmonella, cattle, htrA, purine

\section{INTRODUCTION}

Salmonella spp. are responsible for a variety of enteric infections in humans and domestic animals. Disease signs may vary from mild diarrhoea to systemic disease. In humans, Salmonella enterica serovar Typhi (Salmonella typhi) is the cause of the systemic disease typhoid, whereas other Salmonella serovars, such as $S$. enterica serovar Typhimurium (Salmonella typhimurium), S. enterica serovar Dublin (Salmonella dublin) and S. enterica serovar Enteritidis (Salmonella enteritidis) cause mainly gastroenteritis. S. typhi is not pathogenic in mice but many S. typhimurium isolates can cause systemic infections, thus providing a model of human typhoid (Hormaeche et al., 1995). In cattle, as in humans, S. typhimurium usually causes diarrhoea and

Abbreviations: STSE, Salmonella typhimurium soluble extract; PBS-T, phosphate buffered saline/Tween 20 ; IFN $\gamma$, interferon gamma most infecting bacteria remain associated with tissues of the digestive tract (Jones et al., 1988; Segall \& Lindberg, 1993). The host and bacterial factors that determine whether diarrhoea will develop following challenge are poorly understood.

The murine model of salmonellosis has been exploited to identify genes required for survival and replication in this host (Chiang et al., 1999). Salmonella strains harbouring such mutations are attenuated and therefore are potential live vaccine candidates against salmonellosis in other species (Mastroeni et al., 1999). Thus, the murine salmonellosis model has been used to identify candidate mutations to generate attenuated S. typhi for live typhoid vaccine development. Mutations exploited in this way include those associated with aromatic compound dependence (aro) (Hosieth \& Stocker, 1981; Tacket et al., 2000), purine dependence (pur) (Levine et al., 1987; O'Callaghan et al., 1988; Everest et al., 1997) and stress resistance (htrA) (Chatfield et al., 
1992; Strahan et al., 1992; Tacket et al., 2000). However, not all mutations that attenuate $S$. typhimurium in the murine model are fully attenuating for S. typhi in man. For example, although galE mutants of $S$. typhimurium are attenuated in mice, $S$. typhi galE strains can cause typhoid-like disease in humans (Hone et al., 1988).

In addition to their ability to confer protection against virulent challenge, live attenuated Salmonella vaccines can be used as vectors to deliver antigens from other pathogens, thus bringing the ideal single dose multivalent vaccine closer to reality (Levine \& Dougan, 1998). Few studies have been conducted using Salmonella as a vector for heterologous antigen delivery in species other than the mouse. Studies in cattle have used Salmonella strains harbouring aro mutations (VillarrealRamos et al., 1998). However, in cattle the use of recombinant Salmonella aro mutants as vectors for foreign antigen delivery has been less successful than would have been expected from the results obtained in mice (d'Olivera et al., 1997; Gentschev et al., 1998; Villarreal-Ramos et al., 2000). If attenuated salmonellae are to fulfil their potential as live vaccines against salmonellosis in different animal species it is necessary to evaluate different candidate Salmonella vaccines in the target animal species. Further, it will be essential to explore different delivery regimes and understand the mechanisms of immunity induced by Salmonella vectors in different species. In this work we examined the ability of different mutations that are known to attenuate salmonellae in mice to attenuate salmonellae in cattle. We have also examined the influence of the route of administration on the virulence of Salmonella and the immune response induced.

\section{METHODS}

Bacteria. The S. typhimurium strain 4/74 used for oral and subcutaneous challenge has been described elsewhere (Jones et al., 1991; Rankin \& Taylor, 1966). The purE and htrA mutations were introduced into S. typhimurium 4/74 as described by O'Callaghan et al. (1988) and Chatfield et al. (1992), respectively.

Calves. Four to five week old Friesian bull calves were used throughout. Calves were reared conventionally from birth and tested for the presence of Salmonella as described below. Blood samples were collected by venepuncture from the jugular vein.

Preparation of inocula. For oral challenge, bacteria were grown overnight in Luria-Bertani broth at $37^{\circ} \mathrm{C}$. Appropriate dilutions were made to obtain the number of bacteria required as indicated in the text and in Table 1 for each experiment. The concentration of the inocula was confirmed by plating dilutions on brilliant green agar (Oxoid). Bacteria were resuspended in $20 \mathrm{ml}$ PBS and mixed with an equal volume of antacid solution $(5 \%$ sodium bicarbonate, $5 \%$ magnesium carbonate and $5 \%$ magnesium trisilicate; all from $\mathrm{BDH}$ ) and delivered per os with a syringe (Jones et al., 1988). Calves were inoculated subcutaneously in the prescapular area with bacteria suspended in a final volume of $1.5 \mathrm{ml}$ PBS, preceded by intravenous injection of $2 \mathrm{ml}$ flunixin meglumine at $50 \mathrm{mg} \mathrm{ml}^{-1}$ (Schering-Plough Animal Health) to reduce the risk of hypersensitivity reactions.
Clinical observation of calves. Rectal temperature, faecal consistency, food consumed and general demeanour were recorded. Diarrhoea was scored on a scale from 0 to 3 depending on faecal consistency, with a score of 0 indicating normal faeces and a score of 3 indicating watery scour. One unit was added for the presence of blood and two units for the presence of sloughed mucosa or membrane formation (Jones et al., 1988). Calves that reached a diarrhoea score of 20, failed to eat for two consecutive days, showed a sudden drop in temperature of more than $2{ }^{\circ} \mathrm{C}$ or failed to stand up unaided were killed by intravenous injection of pentobarbitone (May and Baker).

Bacteriological analysis. The presence of Salmonella in faeces before challenge was determined by enrichment in selenite brilliant green broth (SBG) (Difco) and Rappaport medium $[0.45 \%$ tryptone (Difco), $124 \mathrm{mM} \mathrm{NaCl}$ (BDH), $10 \mathrm{mM}$ $\mathrm{KH}_{2} \mathrm{PO}_{4}(\mathrm{BDH}), 180 \mathrm{mM} \mathrm{MgCl}{ }_{2} \cdot 6 \mathrm{H}_{2} \mathrm{O}(\mathrm{BDH}), 0 \cdot 012 \%$ malachite green (BDH)] (Rappaport et al., 1956) and by direct inoculation onto brilliant green agar (Oxoid) for colony counts. The presence of Salmonella in faeces after challenge was determined daily both by enrichment and by direct plating of dilutions of faecal homogenates. Briefly, $1 \mathrm{~g}$ faeces was placed in $9 \mathrm{ml} \mathrm{PBS}, \mathrm{pH} 7.5$ and mixed to obtain a homogeneous suspension. Five drops of $20 \mu$ leach were plated on brilliant green agar plates. The results were expressed as geometric mean counts (g sample $)^{-1}$. Bacteraemia was monitored daily by enrichment of $1 \mathrm{ml}$ blood in SBG and Rappaport medium and subsequent inoculation onto brilliant green agar. After killing the following samples were removed from calves: ileum wall, ileum contents, ileal lymph node (the distal comma shaped node at the end of the chain of jejunoileal lymph nodes), caecum wall, caecum contents, caecal lymph node, colon wall, colon contents, colonic lymph node, liver, hepatic lymph node, spleen, lung, bronchial lymph node, blood and bile. From each sample, $1 \mathrm{~g}$ was placed in $9 \mathrm{ml} \mathrm{H}_{2} \mathrm{O}$ and homogenized, where necessary, using mortar, pestle and sand. Dilutions of the homogenates were plated on brilliant green agar plates as described above. The presence of Salmonella was also determined by enrichment of $1 \mathrm{ml}$ homogenate in SBG and Rappaport medium and subsequent inoculation onto brilliant green agar. Using this technique, the limit of detection by direct plating of bacterial homogenates is 500 bacteria $\mathrm{g}^{-1}$ (i.e. 1 bacterium in a $20 \mu \mathrm{l}$ droplet $=50$ bacteria $\mathrm{ml}^{-1}$ from the original $10 \mathrm{ml}$ homogenate). Therefore, if bacteria were not detected by direct plating but were detected by enrichment in broth, the counts were assumed to be less than 500 bacteria (g sample) $)^{-1}$.

ELISA. ELISA to detect antibodies to LPS was carried out as described by Demarco de Hormaeche et al. (1988). Each well of Microtest III 96-well plates (Falcon) was coated with $2.5 \mu \mathrm{g}$ smooth Westphal LPS from S. typhimurium (Sigma) in $10 \mathrm{mM}$ glycine, $20 \mathrm{mM} \mathrm{NaCl}, 0.2 \mathrm{mM}$ EDTA, $0.01 \mathrm{mM} \mathrm{NaF}$ and $24 \mathrm{mM}$ sodium deoxycholate. After overnight incubation at $37^{\circ} \mathrm{C}$, the plates were incubated with blocking buffer, consisting of $3 \%$ BSA Fraction V (Sigma) in PBS and $0.05 \%$ Tween 20 (Sigma) (PBS-T). After $1 \mathrm{~h}$ at $37^{\circ} \mathrm{C}$, the plates were washed with PBS-T. Fifty microlitres of cattle serum diluted in $0.3 \%$ BSA in PBS-T was added to individual wells in duplicate. To detect IgG1, IgG2 and IgM, sera were diluted 1:1000, $1: 100$ and $1: 100$, respectively. After incubation for $1 \mathrm{~h}$ at $37^{\circ} \mathrm{C}$ the plates were washed and $50 \mu \mathrm{l} \mathrm{B} 37$ (monoclonal antibody to bovine IgG1), B192 (monoclonal antibody to IgG2) or B67 (monoclonal antibody to $\operatorname{IgM}$ ) diluted in $0.3 \%$ BSA in PBS-T was added to each well. Monoclonal antibodies were diluted 1:250, a previously determined optimum concentration. After $1 \mathrm{~h}$ incubation at $37^{\circ} \mathrm{C}$, plates were washed 
Table 1. Outcome of inoculation of calves with $S$. typhimurium 4/74, S. typhimurium 4/74 htrA and S. typhimurium 4/74 purE

ND, Not done; NA, not applicable. + indicates that bacterial cultures were positive for salmonellae after enrichment in SBG or Rappaport medium; - indicates that bacterial cultures were negative for salmonellae after enrichment in SBG or Rappaport medium.

\begin{tabular}{|c|c|c|c|c|c|c|c|}
\hline Calf & Strain & $\begin{array}{c}\text { Route of } \\
\text { inoculation* }\end{array}$ & $\begin{array}{c}\log _{10} \\
\text { inoculum }\end{array}$ & $\begin{array}{l}\text { Outcome } \\
\text { (day of } \\
\text { killing) } \dagger\end{array}$ & $\begin{array}{l}\text { Highest } \\
\text { temp. }\left({ }^{\circ} \mathrm{C}\right) \\
\text { (d) }\end{array}$ & $\begin{array}{l}\log _{10} \text { max. no. } \\
\text { S. typhimurium } \\
(\mathrm{g} \text { faeces })^{-1}(\mathrm{~d})\end{array}$ & $\begin{array}{l}\text { Salmonella in } \\
\text { blood (time) }\end{array}$ \\
\hline 1 & Wild-type & $\mathrm{O}$ & $9 \cdot 17$ & K $(8)$ & $41 \cdot 5(1)$ & $7 \cdot 23(3)$ & $+(3 \mathrm{~d})$ \\
\hline 2 & Wild-type & $\mathrm{O}$ & $9 \cdot 17$ & к (3) & $41 \cdot 2(3)$ & $7 \cdot 74(6)$ & \\
\hline 3 & Wild-type & SC & $9 \cdot 25$ & к (3) & $40 \cdot 7(2)$ & $6 \cdot 69(3)$ & $+(4 \mathrm{~h})$ \\
\hline 4 & Wild-type & SC & $9 \cdot 25$ & K (3) & $41 \cdot 2(1)$ & $8 \cdot 41(4)$ & $+(4 \mathrm{~h})$ \\
\hline 5 & Wild-type & SC & $9 \cdot 17$ & К (7) & $41 \cdot 4(1)$ & $8 \cdot 27(4)$ & $+(4 \mathrm{~h})$ \\
\hline 6 & Wild-type & SC & $9 \cdot 17$ & $\mathrm{~s}$ & $41 \cdot 0(1)$ & $4 \cdot 07(11)$ & $+(4 \mathrm{~h})$ \\
\hline 7 & Wild-type & SC & $9 \cdot 17$ & s & $41 \cdot 1(1)$ & $5 \cdot 39(8)$ & $+(4 \mathrm{~h})$ \\
\hline 8 & Wild-type & SC & $9 \cdot 25$ & s & $40 \cdot 4(4)$ & $4 \cdot 30(16)$ & $+(4 \mathrm{~h})$ \\
\hline 9 & btrA & $\mathrm{O}$ & $10 \cdot 9$ & $\mathrm{~K}(1)$ & NA & NA & NA \\
\hline 10 & btrA & $\mathrm{O}$ & $10 \cdot 9$ & $\mathrm{~K}(1)$ & NA & NA & NA \\
\hline 11 & htrA & $\mathrm{O}$ & $10 \cdot 9$ & $\mathrm{~K}(1)$ & NA & NA & NA \\
\hline 12 & btrA & SC & 10 & s & $40 \cdot 6(1)$ & + & $+(1 \mathrm{~d})$ \\
\hline 13 & btrA & SC & 10 & s & $41(1)$ & + & $+(1 \mathrm{~h})$ \\
\hline 14 & btrA & SC & 10 & s & $41 \cdot 1(2)$ & - & $+(1 \mathrm{~h})$ \\
\hline 15 & btrA & SC & 10 & s & $40 \cdot 9(2)$ & - & $+(1 \mathrm{~d})$ \\
\hline 16 & purE & $\mathrm{O}$ & $10 \cdot 6$ & к $(5)$ & $40 \cdot 5(3)$ & $5 \cdot 77(4)$ & ND \\
\hline 17 & purE & $\mathrm{O}$ & $10 \cdot 6$ & K $(5)$ & $40 \cdot 65(3)$ & $5 \cdot 55(4)$ & ND \\
\hline 18 & purE & $\mathrm{O}$ & $10 \cdot 6$ & к (6) & $40 \cdot 75(3)$ & $6 \cdot 32$ & ND \\
\hline 19 & purE & $\mathrm{O}$ & $10 \cdot 6$ & K (6) & $40 \cdot 45(3)$ & $7 \cdot 11$ & ND \\
\hline 20 & purE & SC & 8 & s & $40 \cdot 15(2)$ & - & ND \\
\hline 21 & purE & SC & 8 & s & $40 \cdot 35(2)$ & - & ND \\
\hline
\end{tabular}

"o, oral; sc, subcutaneous.

† $\mathrm{k}$, killed; s, survived.

with PBS-T and $50 \mu$ l goat anti-mouse horseradish peroxidase conjugate (Dako) diluted $1: 1000$ in $0.3 \%$ BSA in PBS-T was added to each well according to the manufacturer's instructions. After $1 \mathrm{~h}$ at $37^{\circ} \mathrm{C}, 100 \mu \mathrm{l} \mathrm{3,3}, 5,5^{\prime}$-tetramethylbenzidine (ICN), prepared according to the manufacturer's instructions, was added to each well. After $10 \mathrm{~min}, 25 \mu \mathrm{l} 4 \mathrm{M}$ $\mathrm{H}_{2} \mathrm{SO}_{4}$ was added to each well and plates were read at $450 \mathrm{~nm}$ in a Titretek Multiskan MCC/340 ELISA reader.

To detect antibodies to a soluble extract of S. typhimurium (STSE), 96-well plates were coated with $50 \mu \mathrm{l}$ STSE, prepared as described previously (Villarreal et al., 1992), diluted to $2 \mu \mathrm{g} \mathrm{ml}{ }^{-1}$ in $0 \cdot 1 \mathrm{M}$ carbonate buffer $\left[0 \cdot 1 \mathrm{M} \mathrm{Na}_{2} \mathrm{CO}_{3}, 0 \cdot 1 \mathrm{M}\right.$ $\mathrm{NaHCO}_{3}$; both from $\mathrm{BDH}$ ), pH 9.6. After overnight incubation at $4{ }^{\circ} \mathrm{C}$, the plates were incubated for $1 \mathrm{~h}$ at $37^{\circ} \mathrm{C}$ before adding $100 \mu \mathrm{l}$ blocking buffer $[2 \%$ casein (Hammarsten, BDH) in PBS, 0.05\% Tween 20 (Sigma), $\mathrm{pH} 7 \cdot 0$ ] to each well. Thereafter the protocol followed was essentially the same as for the LPS ELISA, except that $0 \cdot 2 \%$ casein in PBS-T was used as the diluent.

Measurement of interferon $\gamma$ (IFN $\gamma$ ) and haptoglobin in sera of cattle inoculated with $S$. typhimurium $4 / 74$. IFN $\gamma$ in sera was measured by ELISA (CSL, Bovigamm) according to the manufacturer's instructions.

The concentration of haptoglobin in sera was assessed using a method based on the preservation of the haemoglobin peroxidase activity of haptoglobin in mild acidic conditions (Makimura \& Suzuki 1982). The method was modified for use on an automated biochemical analyser (MIRA, Roche Diagnostics) to reduce interference from serum albumin (Eckersall et al., 1999). In this method, using the automated biochemical analyser, $2 \cdot 5 \mu \mathrm{l}$ serum was mixed with $200 \mu \mathrm{l}$ of methaemoglobin solution $\left(0.06 \mathrm{mg} \mathrm{ml}^{-1}\right.$ in $\left.0.9 \% \mathrm{NaCl}\right)$, prepared as described by Makimura \& Suzuki (1982). After 50 s, $90 \mu \mathrm{l}$ SB-7 chromogen solution (Tridelta Development) was added. After a further $25 \mathrm{~s}, 50 \mu \mathrm{l} 0 \cdot 12 \% \mathrm{H}_{2} \mathrm{O}_{2}$ substrate (diluted in $\mathrm{H}_{2} \mathrm{O}$ ) was added and the increase in absorbance at $600 \mathrm{~nm}$ over the following $50 \mathrm{~s}$ was monitored. The assay was quantified by comparison with dilutions of a bovine serum sample with a known concentration of haptoglobin, originally being calibrated with purified bovine haptoglobin (Horadagoda et al., 1994).

\section{RESULTS}

\section{Susceptibility of cattle to oral or subcutaneous challenge with $S$. typhimurium 4/74}

Two calves, 1 and 2, were challenged orally with $1.5 \times 10^{9}$ S. typhimurium 4/74 bacteria and, as expected, both calves developed fever and diarrhoea (Table 1). Bacteriological culture of faeces showed that S. typhi- 
Table 2. Bacterial concentrations at post-mortem in tissues of calves inoculated with virulent S. typhimurium 4/74

- indicates that bacterial counts were negative both by plate dilution and by enrichment in SBG or Rappaport medium; + indicates that bacterial counts were negative by plate dilution but positive after enrichment in SBG or Rappaport medium. A blank indicates that the tissue was unavailable.

\begin{tabular}{|c|c|c|c|c|c|c|c|c|}
\hline \multirow[b]{2}{*}{ Route of inoculation... } & \multicolumn{8}{|c|}{$\log _{10}$ bacterial counts $(\mathrm{g} \text { sample })^{-1}$} \\
\hline & \multicolumn{2}{|c|}{ Oral } & \multicolumn{6}{|c|}{ Subcutaneous } \\
\hline Calf... & 1 & 2 & 3 & 4 & 5 & 6 & 7 & 8 \\
\hline \multicolumn{9}{|l|}{ Ileum } \\
\hline Wall & $4 \cdot 00$ & $3 \cdot 96$ & $6 \cdot 79$ & $4 \cdot 53$ & $6 \cdot 73$ & - & - & - \\
\hline Contents & $4 \cdot 38$ & + & $4 \cdot 20$ & $1 \cdot 00$ & $9 \cdot 04$ & - & - & - \\
\hline Lymph node* & $3 \cdot 60$ & $4 \cdot 20$ & 6.95 & $3 \cdot 73$ & $5 \cdot 26$ & - & - & - \\
\hline \multicolumn{9}{|l|}{ Caecum } \\
\hline Wall & $3 \cdot 60$ & + & $3 \cdot 71$ & $4 \cdot 75$ & $8 \cdot 26$ & - & + & - \\
\hline Contents & $5 \cdot 08$ & + & $3 \cdot 32$ & $1 \cdot 78$ & $5 \cdot 36$ & - & + & - \\
\hline Lymph node & $3 \cdot 78$ & $4 \cdot 48$ & $5 \cdot 95$ & $4 \cdot 20$ & $6 \cdot 82$ & - & - & - \\
\hline \multicolumn{9}{|l|}{ Colon } \\
\hline Wall & $4 \cdot 15$ & + & $3 \cdot 41$ & $4 \cdot 98$ & $3 \cdot 94$ & - & + & - \\
\hline Contents & + & + & $2 \cdot 57$ & + & $8 \cdot 52$ & - & + & - \\
\hline Lymph node & $3 \cdot 78$ & $3 \cdot 70$ & $6 \cdot 58$ & $4 \cdot 11$ & $4 \cdot 71$ & - & & - \\
\hline Liver & $3 \cdot 26$ & + & $5 \cdot 57$ & $2 \cdot 18$ & $3 \cdot 60$ & - & - & - \\
\hline Hepatic lymph node & + & + & $7 \cdot 72$ & $3 \cdot 04$ & $4 \cdot 76$ & - & + & - \\
\hline Spleen & + & + & $7 \cdot 77$ & $2 \cdot 00$ & $3 \cdot 75$ & - & - & - \\
\hline Lung & $3 \cdot 66$ & + & $7 \cdot 77$ & $2 \cdot 81$ & $3 \cdot 48$ & - & + & - \\
\hline Bronchial lymph node & + & + & $6 \cdot 64$ & $2 \cdot 69$ & $4 \cdot 00$ & & - & - \\
\hline Blood & + & + & $6 \cdot 00$ & - & $4 \cdot 84$ & - & - & - \\
\hline Bile & - & - & $1 \cdot 30$ & $1 \cdot 00$ & $3 \cdot 48$ & - & - & - \\
\hline
\end{tabular}

* This is the distal, comma-shaped node at the end of the chain of jejuno-ileal lymph nodes.

murium was excreted from the day after inoculation until the day of death. Enrichment of bacteria from blood indicated that calf 2 developed bacteraemia on the third day after inoculation, while no bacteria were detected in the blood of calf 1 . Calves 1 and 2 succumbed to infection on days 8 and 3 after inoculation, respectively, and were killed.

To assess the ability of $S$. typhimurium 4/74 to infect cattle via the parenteral route, six calves were inoculated subcutaneously with $1.5 \times 10^{9}$ (calves 5,6 and 7) or $1 \cdot 8 \times 10^{9}$ (calves 3, 4 and 8) S. typhimurium 4/74 (Table 1). Calves 3,4 and 5 succumbed to infection while calves 6, 7 and 8 survived this high challenge dose. All the subcutaneously challenged cattle developed pyrexia and bacteraemia and secreted S. typhimurium in their faeces (Table 1). Calves 3, 4 and 5 succumbed to infection 3, 3 and $7 \mathrm{~d}$ after inoculation, respectively. Post-mortem bacteriological analysis of killed calves indicated that the salmonellae had spread systemically (Table 2 ). In calves 4 and 5 , the number of $S$. typhimurium $4 / 74$ cells associated with the digestive tract was greater than the number of salmonellae associated with systemic sites such as the spleen, lung and liver. In calf 3 , the number of S. typhimurium 4/74 cells isolated from the spleen, lungs and hepatic nodes was greater than the number of bacteria isolated from the digestive tract tissues. Four to five weeks after inoculation, the calves that survived (6, 7 and 8), were killed and a post-mortem bacteriological analysis performed as indicated in Methods (Table 2). S. typhimurium $4 / 74$ was only detected in one animal after enrichment of organ homogenates.

\section{Susceptibility of calves to challenge with S. typhimurium 4/74 derivatives harbouring mutations in htrA or purE}

To assess the virulence of mutant S. typhimurium 4/74, calves were inoculated orally with $8 \times 10^{10}$ and subcutaneously with $1 \times 10^{10}$ S. typhimurium htrA. All three calves inoculated orally (9,10 and 11), succumbed to salmonellosis the day after inoculation (Table 1). Post-mortem bacteriological analysis revealed that most of the $S$. typhimurium $4 / 74 \mathrm{htrA}$ bacteria were associated with digestive tract tissues. After enrichment of organ homogenates, S. typhimurium 4/74 htrA was also found in the spleen of calf 10 and the lungs of calf 
Table 3. Bacterial concentration at post-mortem in tissues of calves inoculated orally with S. typhimurium 4/74 mutants

+ indicates that bacterial counts were negative by plate dilution but positive after enrichment in SBG or Rappaport medium; - indicates that bacterial counts were negative both by plate dilution and by enrichment in SBG or Rappaport medium. A blank indicates that the tissue was unavailable.

\begin{tabular}{|c|c|c|c|c|c|c|c|}
\hline \multirow{3}{*}{ Inoculated with... } & \multicolumn{7}{|c|}{$\log _{10}$ bacterial counts $(\mathrm{g} \text { sample })^{-1}$} \\
\hline & \multicolumn{3}{|c|}{ S. typhimurium htrA } & \multicolumn{4}{|c|}{ S. typhimurium purE } \\
\hline & 9 & 10 & 11 & 16 & 17 & 18 & 19 \\
\hline \multicolumn{8}{|l|}{ Ileum } \\
\hline Wall & + & $4 \cdot 8$ & + & $5 \cdot 6$ & - & $6 \cdot 7$ & $6 \cdot 3$ \\
\hline Contents & $4 \cdot 9$ & - & + & - & - & - & $6 \cdot 3$ \\
\hline Lymph node* & $3 \cdot 9$ & $4 \cdot 2$ & $3 \cdot 9$ & $3 \cdot 9$ & $3 \cdot 0$ & $3 \cdot 3$ & $5 \cdot 0$ \\
\hline \multicolumn{8}{|l|}{ Caecum } \\
\hline Wall & $3 \cdot 8$ & $3 \cdot 6$ & - & - & $1 \cdot 8$ & $3 \cdot 0$ & $5 \cdot 0$ \\
\hline Contents & $2 \cdot 6$ & - & - & $2 \cdot 3$ & - & $6 \cdot 5$ & $6 \cdot 9$ \\
\hline Lymph node & $3 \cdot 8$ & $4 \cdot 3$ & $3 \cdot 7$ & $4 \cdot 0$ & - & $2 \cdot 5$ & $5 \cdot 0$ \\
\hline \multicolumn{8}{|l|}{ Colon } \\
\hline Wall & $4 \cdot 2$ & - & $5 \cdot 1$ & $3 \cdot 7$ & $2 \cdot 6$ & $3 \cdot 0$ & $6 \cdot 3$ \\
\hline Contents & $3 \cdot 6$ & - & + & - & - & - & $5 \cdot 8$ \\
\hline Lymph node & $4 \cdot 2$ & $4 \cdot 3$ & + & & $2 \cdot 5$ & $2 \cdot 5$ & $6 \cdot 3$ \\
\hline Liver & - & - & - & - & - & - & $2 \cdot 0$ \\
\hline Hepatic lymph node & + & - & $4 \cdot 2$ & - & - & - & $5 \cdot 0$ \\
\hline Spleen & - & + & - & + & - & - & + \\
\hline Lung & - & - & + & - & - & - & - \\
\hline Bronchial lymph node & - & - & - & - & - & - & - \\
\hline Blood & - & - & - & - & - & - & - \\
\hline Bile & - & - & - & - & - & - & - \\
\hline
\end{tabular}

*This is the distal, comma-shaped node at the end of the chain of jejuno-ileal lymph nodes.

11 (Table 3). The four calves inoculated subcutaneously with S. typhimurium htrA (12, 1314 and 15) developed bacteraemia and pyrexia but survived (Table 1). S. typhimurium 4/74 htrA was detected in the blood of these calves between $1 \mathrm{~h}$ and $1 \mathrm{~d}$ after inoculation, and bacteria were also shed in the faeces of three of these calves. As salmonellae were only detected in faeces by broth enrichment, less than 500 bacteria (g faeces) ${ }^{-1}$ were being secreted.

Groups of calves were inoculated orally $(16,17,18$ and $19)$ or subcutaneously (20 and 21) with $3.8 \times 10^{10}$ or $1 \times 10^{8}$ S. typhimurium 4/74 purE respectively. Calves 16 and 17 succumbed to salmonellosis on the fifth day post-inoculation and calves 18 and 19 succumbed on the sixth day after inoculation (Table 1). These calves developed pyrexia and secreted salmonellae in their faeces. Post-mortem bacteriological analysis showed that S. typhimurium 4/74 purE was mainly associated with digestive tract tissues. In two calves, bacteria were isolated either by enrichment or by direct plating from the spleen or the liver. (Table 3). Calves 20 and 21, inoculated subcutaneously, developed pyrexia but did not secrete $S$. typhimurium 4/74 purE in their faeces (Table 1).

\section{Measurement of IFN $\gamma$ and antibodies to LPS in the sera of calves challenged with $S$. typhimurium 4/74}

In a preliminary attempt to relate immunological parameters to susceptibility to infection, the concentrations of IFN $\gamma$ were measured in the sera of infected calves (Table 4). There was no obvious correlation between the concentration of $\operatorname{IFN} \gamma$, the route of inoculation or susceptibility to infection. Calves 1 and 2, inoculated orally, had the highest serum IFN $\gamma$ concentrations on days 2 and 1 respectively. The IFN $\gamma$ concentrations remained higher than they were before inoculation until both calves died. Calves 3, 4, 6 and 7, which were inoculated subcutaneously, had the highest serum IFN $\gamma$ concentrations $1 \mathrm{~d}$ after inoculation, whereas calf 5 had detectable serum IFN $\gamma$ on day one with the highest concentration on day two after inoculation. Calf 8 had detectable serum IFN $\gamma$ on day one after infection with the highest concentration at 6-7 d after inoculation.

Antibodies to LPS and STSE in the sera of calves that survived subcutaneous inoculation of virulent S. typhimurium 4/74 were measured by ELISA. Calf 8 had detectable levels of anti-LPS antibodies prior to chal- 
Table 4. IFN $\gamma$ concentration $\left(\mathrm{ng} \mathrm{ml}^{-1}\right)$ in serum of animals inoculated with $\mathrm{S}$. typhimurium $4 / 74$

ND, not done.

\begin{tabular}{|c|c|c|c|c|c|c|c|c|c|}
\hline \multicolumn{2}{|c|}{$\begin{array}{c}\text { Route of } \\
\text { inoculation... }\end{array}$} & \multicolumn{2}{|c|}{ Oral } & \multicolumn{6}{|c|}{ Subcutaneous } \\
\hline Time & Calf... & 1 & 2 & 3 & 4 & 5 & 6 & 7 & 8 \\
\hline$-1 d$ & & 0.619 & $1 \cdot 71$ & 0 & $0 \cdot 074$ & $2 \cdot 733$ & $0 \cdot 892$ & $1 \cdot 301$ & 0 \\
\hline 0 & & $1 \cdot 642$ & $0 \cdot 824$ & 0 & 0 & $1 \cdot 506$ & $2 \cdot 255$ & $1 \cdot 165$ & 0 \\
\hline $1 \mathrm{~h}$ & & 1.778 & $0 \cdot 347$ & 0 & 0 & $1 \cdot 028$ & $1 \cdot 165$ & $0 \cdot 551$ & 0 \\
\hline $4 \mathrm{~h}$ & & 1.097 & $0 \cdot 415$ & 0 & 0 & $2 \cdot 119$ & $0 \cdot 483$ & 1.983 & 0.892 \\
\hline $1 \mathrm{~d}$ & & $17 \cdot 525$ & $0 \cdot 483$ & $4 \cdot 914$ & $27 \cdot 682$ & 8.595 & $10 \cdot 027$ & $12 \cdot 89$ & $1 \cdot 165$ \\
\hline $2 \mathrm{~d}$ & & $10 \cdot 64$ & $11 \cdot 526$ & $1 \cdot 369$ & $6 \cdot 618$ & $9 \cdot 14$ & $3 \cdot 073$ & $2 \cdot 528$ & $0 \cdot 347$ \\
\hline $3 \mathrm{~d}$ & & 8.936 & $9 \cdot 754$ & 1.097 & $3 \cdot 482$ & $5 \cdot 664$ & $2 \cdot 324$ & $2 \cdot 596$ & 0 \\
\hline $4 \mathrm{~d}$ & & & 6.755 & & $1 \cdot 437$ & $4 \cdot 846$ & $2 \cdot 528$ & $5 \cdot 527$ & 0.074 \\
\hline $5 \mathrm{~d}$ & & & $2 \cdot 937$ & & & $3 \cdot 755$ & $2 \cdot 733$ & $5 \cdot 459$ & 0 \\
\hline $6 \mathrm{~d}$ & & & $\mathrm{ND}$ & & & $2 \cdot 187$ & $2 \cdot 664$ & $6 \cdot 073$ & $2 \cdot 596$ \\
\hline $7 \mathrm{~d}$ & & & $2 \cdot 528$ & & & $4 \cdot 641$ & $2 \cdot 664$ & $7 \cdot 436$ & $2 \cdot 187$ \\
\hline $15 \mathrm{~d}$ & & & & & & & $1 \cdot 301$ & $0 \cdot 892$ & $1 \cdot 028$ \\
\hline
\end{tabular}

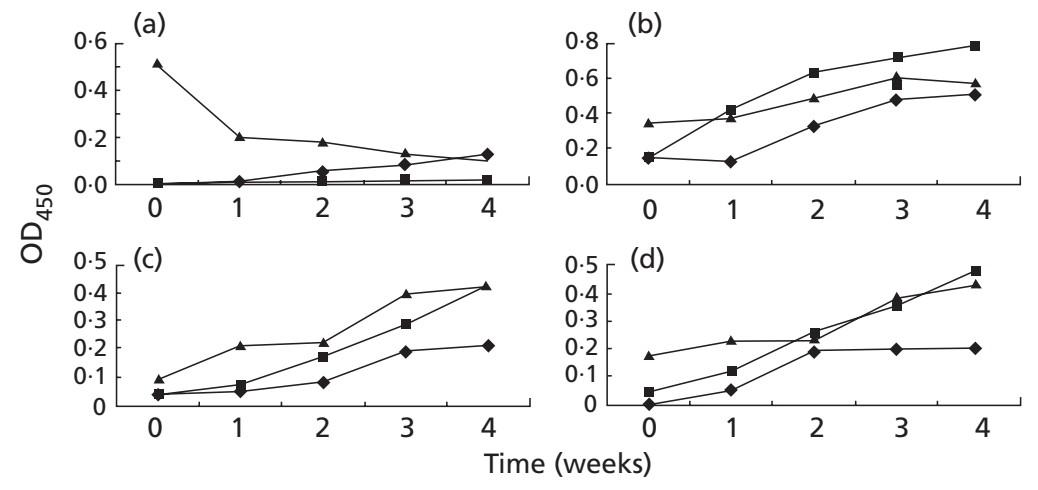

Fig. 1. ELISA to detect antibodies to $S$. typhimurium 4/74 LPS. (a) IgG1 to LPS; (b) IgG1 to STSE; (c) IgG2 to STSE; (d) IgM to STSE. To detect IgG1, $\lg G 2$ and IgM sera were diluted $1: 1000,1: 100$ and $1: 100$, respectively. $\diamond$, calf $6 ; \boldsymbol{\square}$, calf $7 ; \boldsymbol{\Delta}$, calf 8 .

Table 5. Haptoglobin $\left(\mathrm{mg} \mathrm{ml}^{-1}\right)$ in serum of cattle inoculated with $S$. typhimurium $4 / 74$

\begin{tabular}{|c|c|c|c|c|c|c|c|c|c|}
\hline \multicolumn{2}{|c|}{$\begin{array}{c}\text { Route of } \\
\text { inoculation... }\end{array}$} & \multicolumn{2}{|c|}{ Oral } & \multicolumn{6}{|c|}{ Subcutaneous } \\
\hline Days & Calf... & 1 & 2 & 3 & 4 & 5 & 6 & 7 & 8 \\
\hline 0 & & $0 \cdot 03$ & $0 \cdot 02$ & $0 \cdot 07$ & 0 & $0 \cdot 02$ & $0 \cdot 02$ & $0 \cdot 87$ & 0.02 \\
\hline 1 & & $0 \cdot 04$ & $0 \cdot 03$ & $0 \cdot 02$ & 0.56 & $0 \cdot 28$ & $0 \cdot 32$ & 0.56 & $0 \cdot 15$ \\
\hline 2 & & 0.03 & $0 \cdot 12$ & $0 \cdot 24$ & 0.55 & $0 \cdot 29$ & $0 \cdot 13$ & $0 \cdot 84$ & 0.04 \\
\hline 3 & & $0 \cdot 02$ & $0 \cdot 11$ & $0 \cdot 01$ & $0 \cdot 1$ & $0 \cdot 23$ & $0 \cdot 21$ & $0 \cdot 5$ & 0.05 \\
\hline 4 & & & $0 \cdot 03$ & & $0 \cdot 08$ & $0 \cdot 08$ & $0 \cdot 09$ & $0 \cdot 36$ & $0 \cdot 02$ \\
\hline 5 & & & $0 \cdot 04$ & & & $0 \cdot 04$ & $0 \cdot 04$ & $0 \cdot 28$ & $0 \cdot 05$ \\
\hline 6 & & & & & & $0 \cdot 03$ & $0 \cdot 02$ & 0.57 & $0 \cdot 02$ \\
\hline 7 & & & & & & $0 \cdot 02$ & $0 \cdot 02$ & $0 \cdot 85$ & 0.02 \\
\hline
\end{tabular}

lenge and the concentration declined after inoculation (Fig. 1a). Calf 7 did not produce detectable levels of antiLPS throughout the experiment, while calf 6 had a slight increase in the relative concentration by weeks 3 and 4 . $\operatorname{IgG} 2$ or $\operatorname{Ig} M$ antibody to LPS was not detected in any of the calves. We assayed for the presence of antibodies to STSE by ELISA (Fig. 1b-d) in the same sera. Although there were differences in the responses of individual animals, all calves produced detectable IgG1, IgG2 and IgM to STSE after challenge. 


\section{Measurement of haptoglobin in sera of inoculated calves}

In five out of six cattle inoculated subcutaneously with S. typhimurium 4/74, an increase in the concentration of serum haptoglobin was apparent, reaching a peak of between $0.15 \mathrm{mg} \mathrm{ml}^{-1}$ and $0.56 \mathrm{mg} \mathrm{ml}^{-1}$ on days one and two after infection (Table 5). A relatively high concentration of serum haptoglobin was detected in calf 8 prior to inoculation. In this calf the concentration of haptoglobin in serum did not increase beyond that detected on day 0 . In the calves inoculated orally ( 1 and 2 ) the haptoglobin response was low in one animal $\left(<0.12 \mathrm{mg} \mathrm{ml}^{-1}\right)$ and hardly detectable in the other (Table 5). Thus, there was a detectable difference between the route of inoculation and the acute phase reaction as identified by alterations in the concentration of serum haptoglobin.

\section{DISCUSSION}

We have compared the outcome of inoculation of calves using either the oral or the subcutaneous route of challenge with wild-type $S$. typhimurium 4/74 and $S$. typhimurium 4/74 htrA and $S$. typhimurium 4/74 purE mutants. Interestingly, in contrast to results obtained in mice, both the S. typhimurium htrA and S. typhimurium 4/74 purE derivatives were virulent for calves after oral challenge. Although calves inoculated subcutaneously with S. typhimurium 4/74 generally survived, those inoculated orally mostly succumbed to salmonellosis. The outcomes of the inoculation of calves with $S$. typhimurium 4/74 purE or htrA indicated a major difference in the behaviour of these $S$. typhimurium mutants in calves and mice in terms of the level of attenuation. Taking these observations together with the different influences of the route of challenge between mice and cattle, the data suggest a fundamental difference in the pathogenesis of salmonellosis between the two species. We confirmed previous observations (Jones et al., 1991; Watson et al., 1998) showing that calves of four weeks of age inoculated orally with $10^{8}-10^{9}$ S. typhimurium $4 / 74$ succumb to salmonellosis. In contrast, calves inoculated subcutaneously with around $10^{9}$ S. typhimurium 4/74 generally survived. Other workers have suggested that salmonellosis is more reliably induced by the subcutaneous route than by oral inoculation (Bairey, 1978). However, the dose they used $\left(5 \times 10^{9} \mathrm{~S}\right.$. typhimurium $)$, although affecting the animals, failed to induce diarrhoea. We assessed the potential of parenteral use of attenuated Salmonella strains, as this would facilitate immunological evaluation of vaccine candidates and help in measuring immune responses in local draining lymph nodes. In our preliminary experiments, calves were inoculated subcutaneously with $1 \times 10^{9} \mathrm{~S}$. typhimurium 4/74, which induced clinical symptoms and diarrhoea, and in some cases death. Although S. typhimurium can spread systemically in cattle, systemic organs do not appear to be the primary site of bacterial growth. Thus, in cattle, the primary target organ may be the gut and associated lymphoid tissues, and this targeting may be partially independent of the route through which S. typhimurium enters the host. These findings are consistent with $S$. typhimurium being mainly a systemic, rather than a gastroenteric, pathogen in mice, but mainly a gastroenteric pathogen in calves. In agreement with this hypothesis, Tsolis et al. (1999) have reported that virulence-associated factors linked with intestinal penetration, such as SPI-1, seem to be more important for pathogenicity in calves than genes required during the systemic phase of infection, such as SPI-2. These differences have also been supported by studies in cattle (Watson et al., 1998) and rabbits (Everest et al., 1999), both of which develop diarrhoea associated with $S$. typhimurium infections. Either the gut lumen or the gutassociated tissues may provide a suitable site for replication of salmonellae. In addition, the function of intestinal cells in cattle appears to be more susceptible to disruption compared to mice, leading to fluid loss and diarrhoea.

The difference in pathogenesis of S. typhimurium in cattle and mice is of relevance in the design and development of safe and effective vaccines. This is particularly important as the mouse is now most frequently used as the animal of choice for identifying potentially attenuating gene mutations in Salmonella spp. Indeed, mutations in both the aro and $h t r A$ genes were originally identified as attenuating in mice and were subsequently used as components of rationally attenuated $S$. typh $i$ vaccine candidates. Mutations in aro genes have been shown to significantly attenuate Salmonella strains in several animal species including cattle (Smith et al., 1984; Jones et al., 1991) and humans (Tacket et al., 1992). Mutations in $h t r A$ were also used to prevent the detectable systemic spread of S. typhi in volunteers challenged with $S$. typhi aro vaccines (Tacket et al., 2000). The htrA gene encodes a periplasmic protease which increases the resistance of salmonellae to peroxide and which appears to contribute to the ability of salmonellae to resist the bactericidal action of macrophages (Johnson et al., 1991). The apparent virulence of $S$. typhimurium $4 / 74 \mathrm{htr} A$ in calves after oral challenge may reflect differences in the ability of bovine macrophages to kill S. typhimurium. Alternatively, S. typhimurium may grow in different host sites in bovine tissues. However, at this time we cannot rule out the possibility that other Salmonella strains may be attenuated by $h \operatorname{tr} A$ or purE mutations in cattle.

IFN $\gamma$ can be produced by T cells and NK (natural killer) cells in response to exposure to bacterial antigens. In naïve animals IFN $\gamma$ is produced predominantly by $\mathrm{NK}$ cells. In mice IFN $\gamma$ can be detected in vivo in the sera of mice inoculated intravenously with salmonellae $3 \mathrm{~d}$ after inoculation (Mastroeni et al., 1996; Ramarathinam et al., 1991). Depletion of IFN $\gamma$ during the early stages of salmonellosis in mice led to an increase in the rate of growth of virulent salmonellae (Muotiala \& Makela, 1990). Equally, administration of exogenous IFN $\gamma$ in the early stages of salmonellosis in mice leads to a decrease in the rate of growth of salmonellae (Muotiala \& Makela, 1990). We looked for a relationship between 
the route of infection and production of IFN $\gamma$ in cattle inoculated with $S$. typhimurium $4 / 74$, but found no correlation. Calves inoculated orally or subcutaneously that either survived or succumbed to the infection produced IFN $\gamma$. An acute phase reaction has been demonstrated in cattle infected with S. typhimurium. The production of haptoglobin is stimulated during the acute phase reaction by a combination of pro-inflammatory cytokines such as interleukin 1 (IL-1), IL-6 and $\mathrm{TNF} \alpha$ being released from macrophages and other cells at the site of lesions or infection. Potentially, IFN $\gamma$ can be involved in this pathway by activation of macrophages, but in our studies, with the difference between the subcutaneous and oral routes of inoculation it would appear that the IFN $\gamma$ and haptoglobin responses were not correlated. The acute phase response detected in the subcutaneously inoculated cattle was moderate. Recent studies show that the acute phase response to conditions such as clinical mastitis, pulmonary thromboembolism and acute respiratory disease can lead to serum concentrations of $2-3 \mathrm{mg}$ haptoglobin $\mathrm{ml}^{-1}$ (Horadagoda et al., 1999) and here we observed a rise to only about $25 \%$ of these levels. The acute phase response is not likely to be a useful diagnostic tool in orally infected cases of salmonellosis (e.g. natural infection), but could be a useful tool in experimental infection, especially for monitoring the response to subcutaneous inoculation.

In conclusion, our studies, taken together with those of others, highlight significant differences in the pathogenesis of salmonellosis between mice and cattle. This conclusion is supported by data obtained using different routes of challenge and different mutations that influence the growth of salmonellae in vivo. Further studies using different Salmonella strains deleted in different genes should be of value in identifying the differences in basic pathogenic mechanisms and improve our understanding of host specificity in Salmonella, a poorly understood area at the present time.

\section{ACKNOWLEDGEMENTS}

This work was supported by grants from The Wellcome Trust and the BBSRC.

\section{REFERENCES}

Bairey, M. S. (1978). Immunization of calves against salmonellosis. J Am Vet Med Assoc 173, 610-614.

Chatfield, S. N., Strahan, K., Pickard, D., Charles, I. G., Hormaeche, C. E. \& Dougan, G. (1992). Evaluation of Salmonella typhimurium strains harbouring defined mutations in $h \operatorname{tr} A$ and $\operatorname{aro} A$ in the murine salmonellosis model. Microb Pathog 12, 145-151.

Chiang, S. L., Mekalanos, J. J. \& Holden, D. W. (1999). In vivo genetic analysis of bacterial virulence. Annu Rev Microbiol 53, 129-154.

Demarco de Hormaeche, R., Jessop, H. \& Senior, K. (1988). Gonococcal variants selected by growth in vivo or in vitro have antigenically different LPS. Microb Pathog 4, 289-297.

Eckersall, P. D., Duthie, S., Moffatt, D., Horadagoda, N. U., Doyle, S., Parton, R., Bennett, D. \& Fitzpatrick, J. L. (1999). An automated biochemical assay for haptoglobin: prevention of interference from albumin. Comp Haematol Int 9, 117-124.
Everest, P., Allen, J., Papaconstantinopoulou, P., Mastroeni, P., Roberts, M. \& Dougan, G. (1997). Salmonella typhimurium infections in mice deficient in interleukin-4 production : role of IL4 in infection associated pathology. J Immunol 159, 1820-1827.

Everest, P., Ketley, J., Hardy, S., Douce, G., Khan, S., Shea, J., Holden, D., Maskell, D. \& Dougan, G. (1999). Evaluation of Salmonella typhimurium mutants in a model of experimental gastroenteritis. Infect Immun 67, 2815-2821.

Gentschev, I., Glaser, L., Goebel, W., McKeever, D. J., Musoke, A. \& Heussler, V. T. (1998). Delivery of the p67 sporozoite antigen of Theileria parva by using recombinant Salmonella dublin: secretion of the product enhances specific antibody responses in cattle. Infect Immun 66, 2060-2064.

Hoiseth, S. K. \& Stocker, B. A. (1981). Aromatic-dependent Salmonella typhimurium are non-virulent and effective as live vaccines. Nature 291, 238-239.

Hone, D. M., Attridge, S. R., Forrest, B., Morona, R., Daniels, D., LaBrooy, J. T., Bartholomeusz, R. C., Shearman, D. J. \& Hackett, J. (1988). A galE via (Vi antigen-negative) mutant of Salmonella typhi Ty2 retains virulence in humans. Infect Immun 56, 1326-1333.

Horadagoda, A., Eckersall, P. D., Hodgson, J. C. \& Gibbs, H. A. (1994). Immediate responses in serum $T N F \alpha$ and acute phase protein concentrations to infection with Pasteurella haemolytica A1 in calves. Res Vet Sci 57, 129-132.

Horadagoda, N. U., Knox, K. M. G., Gibbs, H. A., Reid, S. W. J., Horadagoda, A., Edwards, S. E. R. \& Eckersall, P. D. (1999). Acute phase proteins in cattle: discrimination between acute and chronic inflammation. Vet Rec 144, 437-444.

Hormaeche, C. E., Khan, C. M. A., Mastroeni, P., Villarreal, B., Dougan, G., Roberts, M. \& Chatfield, S. N. (1995). Salmonella vaccines: mechanisms of immunity and their use as carriers of recombinant antigens. In Molecular and Clinical Aspects of Bacterial Vaccine Development, pp. 119-153. Edited by D. A. A. Ala'Aldeen \& C. E. Hormaeche. Guilford: Wiley.

Johnson, K. J., Charles, I. G., Miller, I. A., Pickard, D., O'Goara, P., Costa, G., Ali, T. \& Hormaeche, C. E. (1991). The role of a stressresponse protein in Salmonella typhimurium virulence. Mol Microbiol 5, 401-407.

Jones, P. W., Collins, P. \& Aitken, M. M. (1988). Passive protection of calves against experimental infection with Salmonella typhimurium. Vet Rec 123, 536-541.

Jones, P. W., Dougan, G., Hayward, C., Mackensie, N., Collins, P. \& Chatfield, S. N. (1991). Oral vaccination of calves against experimental salmonellosis using a double aro mutant of Salmonella typhimurium. Vaccine 9, 29-34.

Levine, M. M. \& Dougan, G. (1998). Optimism over vaccines administered through mucosal surfaces. Lancet 351, 1375-1376.

Levine, M. M., Herrington, D., Murphy, J. R. \& 8 other authors (1987). Safety, infectivity, immunogenicity and in vivo stability of two attenuated auxotrophic mutant strains of Salmonella typhi, $541 \mathrm{Ty}$ and $543 \mathrm{Ty}$ as live oral vaccines in humans. J Clin Invest 79, 888-902.

Makimura, S. \& Suzuki, N. (1982). Quantitative determination of bovine serum haptoglobin and its elevation in some inflammatory diseases. Jpn J Vet Sci 44, 15-21.

Mastroeni, P., Harrison, J. A., Chabalgoity, J. A. \& Hormaeche, C. E. (1996). Effect of interleukin 12 neutralization on host resistance and gamma interferon production in mouse typhoid. Infect Immun 64, 189-196.

Mastroeni, P., Bowe, F., Simmons, C., Cahill, R. \& Dougan, G. (1999). Vaccines against gut pathogens. Gut 45, 633-635. 
Muotiala, A. \& Makela, P. H. (1990). The role of IFN $\gamma$ in murine Salmonella typhimurium infection. Microb Pathog 8, 135-141.

O'Callaghan, D., Maskell, D., Liew, F. Y., Easmon, C. S. F. \& Dougan, G. (1988). Characterization of aromatic- and purinedependent Salmonella typhimurium: attenuation, persistence, and ability to induce protective immunity in BALB/c mice. Infect Immun 56, 419-423.

d'Oliveira, C., Feenstra, A., Vos, H., Osterhaus, A. D. M. E., Shiels, B. R., Cornelissen, A. W. C. A. \& Jongejan, F. (1997). Induction of protective immunity to Theileria annulata using two major merozoite surface antigens presented by different delivery systems. Vaccine 15, 1796-1804.

Ramarathinam, L., Shaban, R. A., Niesel, D. W. \& Klimpel, G. R. (1991). Interferon gamma (IFN- $\gamma$ ) production by gut-associated lymphoid tissue and spleen following oral Salmonella typhimurium challenge. Microb Pathog 11, 347-356.

Rankin, J. D. \& Taylor, R. J. (1966). The estimation of doses of Salmonella typhimurium suitable for the experimental production of disease in calves. Vet Rec 78, 706-707.

Rappaport, F., Konforti, N. \& Navon, B. (1956). A new enrichment medium for certain salmonellae. J Clin Pathol 9, 261-266.

Segall, T. \& Lindberg, A. A. (1993). Oral vaccination of calves with an aromatic-dependent Salmonella dublin $(\mathrm{O} 9,12)$ hybrid expressing $\mathrm{O} 4,12$ protects against $S$. dublin $(\mathrm{O} 9,12)$ but not against Salmonella typhimurium (O4,5,12). Infect Immun 61, 1222-1231.

Smith, B. P., Reina-Gurra, M., Stocker, B. A., Hosieth, S. K. \& Johnson, E. (1984). Aromatic-dependent Salmonella dublin as a parenteral modified live vaccine for calves. Am J Vet Res 45, 2231-2235.

Strahan, K., Chatfield, S. N., Tite, J., Dougan, G. \& Hormaeche, C. (1992). Impaired resistance to infection does not increase the virulence of Salmonella $h t r A$ live vaccines for mice. Microb Pathog 12, 311-317.

Tacket, C. O., Hone, D. M., Losonsky, G. A., Guers, L., Edelman, R. \& Levine, M. M. (1992). Clinical acceptability and immunogenicity of CVD908 Salmonella typhi vaccine strain. Vaccine 10, 443-446.

Tacket, C. O., Sztein, M. B., Wasserman, S. S. \& 11 other authors (2000). Phase 2 clinical trial of attenuated Salmonella enterica serovar typhi oral live vector vaccine CVD 908-htrA in U.S. volunteers. Infect Immun 68, 1196-1201.

Tsolis, R. M., Adams, L. G., Ficht, T. A. \& Bäumler, A. J. (1999). Contribution of Salmonella typhimurium virulence factors to diarrheal disease in calves. Infect Immun 67, 4879-4885.

Villarreal, B., Mastroeni, P., Demarco de Hormaeche, R. \& Hormaeche, C. E. (1992). Proliferative and T-cell specific interleukin (IL-2/IL-4) production responses in spleen cells from mice vaccinated with aroA live attenuated Salmonella vaccines. Microb Pathog 13, 305-315.

Villarreal-Ramos, B., Manser, J., Collins, R. A., Dougan, G., Chatfield, S. N. \& Howard, C. (1998). Immune responses in calves immunised orally or subcutaneously with a live Salmonella typhimurium aro vaccine. Vaccine 16, 45-54.

Villarreal-Ramos, B., Manser, J. M., Collins, R. A., Dougan, G. \& Howard, C. J. (2000). Cattle immune responses to tetanus toxoid elicited by recombinant Salmonella typhimurium vaccines or tetanus toxoid in alum or Freund's adjuvant. Vaccine 14, 1515-1521.

Watson, P. R., Galyov, E. E., Paulin, S. M., Jones, P. W. \& Wallis, T. S. (1998). Mutation of invH, but not stn, reduces Salmonellainduced enteritis in cattle. Infect Immun 66, 1432-1438.

Received 28 March 2000; revised 21 July 2000; accepted 10 August 2000. 